\title{
RELAÇÕES DE GÊNERO NAS AULAS DE MATEMÁTICA: PERCEPTIVEIS OU OCULTAS?
}

\section{Gender relation in mathematics classes: perceptible or hidden?}

Lindamir Salete Casagrande ${ }^{4}$ Marilia Gomes de Carvalho ${ }^{5}$

\section{Resumo:}

O objetivo deste artigo é apresentar resultados parciais de uma pesquisa cujo objetivo foi verificar como acontecem as relações de gênero nas aulas de Matemática de $5^{\mathrm{a}}$ a $8^{\mathrm{a}}$ séries do ensino fundamental em um Colégio da rede estadual de educação de Curitiba no Paraná. Para a realização da pesquisa utilizou-se o método etnográfico que possibilita a observação dos múltiplos eventos que ocorrem em uma determinada comunidade, no caso, a sala de aula de Matemática. As relações de gênero foram analisadas em quatro turmas da faixa escolar determinada, uma de cada série. O Colégio

4 Licenciada em Ciências com habilitação em Matemática. Mestra e doutora em Tecnologia pelo PPGTE/ UTFPR. Pós-doutoranda em Estudos interdisciplinares sobre mulheres, gênero e feminismo - PPGNEIM/UFBA. Pesquisadora do Núcleo de Gênero e Tecnologia - GeTec/PPGTE/UTFPR; professora do Departamento Acadêmico de Matemática da UTFPR e professora colaboradora do Programa de Pós-Graduação em Tecnologia - PPGTE; coordenadora editorial dos Cadernos de Gênero e Tecnologia. Organizadora dos livros "Igualdade na Diversidade: enfrentando o sexismo e a homofobia" e "Construindo a igualdade na diversidade: gênero e sexualidade na escola". Tem pesquisas e publicações na área de Gênero e Educação, Mulher e Ciência e Bullying. E-mail: lindasc@utfpr.edu.br.

5 Doutora em Antropologia Social - USP; Pós-Doutora pela Université de Technologie de Compiègne-Frça;Professorara do Programa de Pós-Gaduação em Tecnologia - PPGTE da Universidade Tecnológica Federal do Paraná - UTFPR; Pesquisadora do Núcleo de Gênero e Tecnologia - GeTec/PPGTE/ UTPR; Autora e Organizadora dos livros: "Ciência, Tecnologia e Gênero; abordagens iberoamericanas". Ed. UTFPR, Curitiba, 2011. "Construindo a Igualdade na Diversidade: gênero e sexualidade na escola". Ed UTFPR, Curitiba, 2009. 'Diversidad Cultural, Género y Tecnología: un abordage interdisciplinario. Ed. UTFPR, Curitiba, 2006. E-mail: mariliagdecarvalho@gmail.com. 
escolhido para a pesquisa tem mais de cem anos de funcionamento e está localizado na região central de Curitiba. Realizei observações, entrevistas e análise de documentos. Os resultados apontam para relações diferenciadas entre meninos e meninas com a Matemática e entre os/as colegas bem como com o/a professor/a.

Palavras - chave: Relações de gênero; Escola; Alunos e Alunas; Educação; Aulas de Matemática.

\section{Abstract}

The objective of this paper is to present partial results of a research whose goal was to happen as gender relations in Mathematics classes from 5th to 8th grades of elementary school in a state college of the Curitiba education in Parana. For the research we used the ethnographic method that allows the observation of multiple events occurring in a particular community, in this case, the Mathematics classroom. Gender relations were analyzed in four groups of specific school-age children, one in each series. The College chosen for the survey is over a hundred years of operation and is located in central region of the Curitiba. Realized observations, interviews and document analysis. The results point to different relationships between boys and girls with mathematics and between her and his colleagues as well as with the teachers.

Key-words: Gender Relations; School; Men and Women Students; Education; Mathematics Classes.

\section{Introdução}

Este artigo tem como objetivo apresentar uma parcela dos resultados da pesquisa para a elaboração da tese de doutorado intitulada Entre silenciamentos e invisibilidades: as relações de gênero no cotidiano das aulas de Matemática defendida em 09/12/2011. Visa ainda contribuir para a discussão da temática de gênero e educação no meio acadêmico. Para o desenvolvimento da pesquisa foi utilizado o método etnográfico que prevê vários procedimentos de coleta de dados, dos quais foram utilizados a entrevista, a observação e a análise de documentos (SARMENTO, 2003). Os resultados aqui apresentados são oriundos da triangulação dos dados obtidos por meio 
das três formas de coleta/produção de dados.

A pesquisa foi realizada em um colégio da rede estadual de educação localizado na região central de Curitiba em quatro turmas do ensino fundamental, $5^{a}$ a $8^{a}$ séries $^{6}$. Fez-se observação por seis meses nas aulas de Matemática das turmas selecionadas. Destas turmas foram entrevistados/ as quarenta estudantes (vinte de cada sexo e dez de cada turma) e os/as professores/as de Matemática (dois homens e duas mulheres). Fez-se a análise de documentos que continham as notas de Matemática dos/as alunos/as destas quatro turmas

A motivação para esta pesquisa se deu pelo desejo de conhecer um pouco mais sobre a temática gênero e educação, de modo especial, nas aulas de Matemática. Outro fator a influenciar foi a minha formação em Licenciatura em Matemática que me desperta interesse em estudar esta disciplina. Esta era a oportunidade de unir duas paixões, os estudos de gênero e a Matemática.

Para a realização desta pesquisa partiu-se do pressuposto de que o gênero é uma das categorias importantes nos estudos sobre a sociedade. A categoria gênero pode ser entendida "como uma linguagem, uma forma de comunicação e ordenação do mundo, que orienta a conduta das pessoas em suas relações específicas, e que é, muitas vezes, base para preconceitos, discriminação e exclusão social" (SIMIÃO, 2005: p. 13). Para Felipe e Guizzo (2003: p. 121), gênero está "relacionado fundamentalmente aos significados que são atribuídos ao ser mulher ou ao ser homem em diferentes sociedades e épocas".

Considera-se que o gênero é social e culturalmente construído e por tanto, pode ser modificado, desconstruído, reconstruído. Representa e estabelece relações de poder entre os sujeitos de cada gênero e mesmo entre sujeitos do mesmo gênero (SCOTT, 1995; COSTA, 1994). Assim, todos os segmentos da sociedade contribuem para esta construção, inclusive a escola e os sujeitos que nela atuam. Sem dúvida, a sala de aula é um espaço de poder, de construção das identidades, e analisar o que ali ocorre é fun- 
damental para compreender como meninas e meninos exercem o poder na concepção de Foucault.

Ao adotar a visão relacional de gênero entende-se que "a superação da lógica binária contida na proposta da análise relacional de gênero [...] é fundamental para que se construa um novo olhar aberto às diferenças" (RAGO, 1998, p. 98). Permite a percepção de que as diferenças não significam desigualdades, ou seja, nem inferior, nem superior, apenas diferente.

Com relação à escola, parte-se do pressuposto de que ela não atua somente como mantenedora da cultura dominante e das regras estabelecidas pela sociedade. Pode ser um instrumento importante na transformação de tais normas para assegurar a todos/as o direito à educação. Desta forma, tem papel importante na construção das identidades de gênero dos/as estudantes, porém não é a única instituição responsável por esta construção. Outras instituições como família e igreja, além da mídia e do convívio em sociedade contribuem de forma significativa para esta construção. Como a pesquisa aqui apresentada foi realizada na escola, o artigo versará sobre o seu papel nesta construção, porém sempre tendo em mente as demais instâncias que constituem os sujeitos.

Com este olhar adentrei a sala de aula e observei o que ocorria lá. $O$ olhar estava voltado para as relações de gênero, objeto da pesquisa, porém as questões de raça/etnia, de classe, de orientação sexual também se faziam presentes.

\section{As relações de gênero nas aulas de Matemática}

Com base nas observações e nas entrevistas pude perceber que os/ as estudantes preferiam se relacionar com colegas do mesmo sexo. Raramente interagiam com colegas do sexo oposto. Eles/as afirmavam que a diferença de interesse era fator determinante para esta preferência como pode ser percebido nos trechos de entrevistas a seguir. Este fato fazia com que eles/as se unissem no clubinho do "bolinha" e da "luluzinha"7. Nestes "clubes" não se permite o ingresso de jovens de outro sexo. Ao se unirem nestes grupos não se propicia a relação entre estudantes de sexos distintos. A necessidade de pertencimento ao grupo pode inibir os/as jovens que

Termos utilizados pelos jovens para designar grupos de meninos e de meninas. 
gostariam de quebrar esta fronteira.

Este fato diminuía com o passar dos anos. $\mathrm{Na} 7^{\mathrm{a}}$ e $8^{\mathrm{a}}$ série havia mais interação entre os/as colegas de sexo diferente, porém, permanecia rara. Este tipo de relacionamento dificultava que os/as estudantes conhecessem as experiências e comportamentos dos/as colegas do outro sexo, conhecimento este fundamental para o dia a dia e deixassem de aprender com o outro. A interação ocorria nos momentos de brincadeiras e de lazer, raramente os/as jovens se reuniam para estudar ou para tirar dúvidas. Sabe-se que a troca de conhecimento entre colegas contribui para a construção do conhecimento e pode resultar em aprendizado tanto de conteúdo quanto de relações sociais.
$A^{8}$ : por que você se relaciona melhor com elas?
$\mathrm{B}$ : porque eu acho que como menina... as meninas me enten- dem melhor:::
A: você acha que os assuntos dos piá ${ }^{9}$ e das meninas são diferentes?
B: são diferentes... alguns são iguais, mas a maioria são difer- entes (Vitória, da $5^{\mathrm{a}}$ série)
A: no teu grupo de amigos tem mais meninos ou meninas?
B: meninos
A: por que você acha que isso acontece?
B: ah pelo fato de eu ser menino né ...porque sei lá... meni- no gosta de ... futebol :..: de computador ... disso daí né e daí menina já gosta de outro tipo de coisa ...dai o assunto não é o mesmo. (Francisco, $6^{\mathrm{a}}$ série)

Esta preferência era baseada em estereótipos sobre o que é ser homem ou ser mulher. Demonstra que eles/as estão impregnados da forma dicotômica de viver a masculinidade e a feminilidade. Indica que desde muito cedo os/as jovens têm suas identidades de gênero construídas com base em papéis sociais atribuídos a um e a outra. Essa construção é feita por meio das múltiplas instituições que interferem na formação dos/as jovens. Evidencia ainda que a socialização diferenciada de meninos e meninas se faz notar na fala de Francisco. É possível deduzir que, na opinião dele, meninas não gostam de futebol e computador, e, por outro lado, os meninos não podem se interessar pelos assuntos que as meninas gostam de comentar.

No trecho da entrevista com Gervásia citado a seguir percebe-se que

8 A letra "A" indica a fala da entrevistadora e "B" a fala do/a entrevistado/a. 
ela demonstrava dificuldade no relacionamento com meninos. Esta era a tônica de muitos/as entrevistados/as que evidenciavam tal dificuldade. Sendo a escola um espaço que propicia o convívio entre meninos e meninas, esta dificuldade ou até recusa de relacionamento é um indicativo da construção dos gêneros com papéis diferenciados. Parecia que meninos e meninas viviam em mudos separados mesmo unidos no mesmo espaço físico.
A: No teu grupo de amigos...
$B$ : Menina... eu quase nem tenho... nem converso muito com os piá... as vezes eles pedem... a única coisa que eu falo ... as vezes eles pedem dá uma bala... só ... agora mesmo eu con- versei com o Adriano sobre o trabalho... só assim.
A: Mas por quê você acha que tem mais meninas?
B: Por que ...ai:.:. eh que é estranho falar com meninos... ah eu não me dou bem... eu acho estranho... eu não gosto muito... prefiro mesmo menina... (Gervásia, $6^{a}$ série)

$\mathrm{Na} 8^{\mathrm{a}}$ série observei um fato que pode justificar a pouca relação entre colegas de sexo distinto para o estudo. O comentário do professor constante no excerto a seguir sobre o fato do menino se unir com a menina para resolução dos exercícios causou constrangimento em ambos e no restante das aulas que observei, eles não aproximaram mais as carteiras para estudar, continuavam conversando, mas cada um tentava resolver os exercícios em sua carteira. Percebeu-se que a postura dos/as professores é um dos fatores que dificulta a interação entre estudantes de diferentes sexos e pode desestimular a cooperação entre os jovens.

*Você vai juntar com a Eliane, quem sabe já rola um romance. * A turma ri, a aluna fica vermelha e o aluno derruba o penal ${ }^{10}$. (DC ${ }^{11}, 8^{a}$ série $\left.24 / 09 / 2009\right)$

Os/as estudantes percebiam que existia diferença na forma como alunos e alunas se relacionavam entre si e com a Matemática. Elas eram vistas como mais caprichosas, dedicadas e obedientes e eles como mais questionadores e ativos. Esta ideia perpassava a fala de meninos e meninas e evidenciava a perpetuação dos estereótipos construídos socialmente como características masculinas e femininas. Os/as estudantes não percebiam

10 Forma curitibana de se referir ao estojo para lápis e canetas.

11 Diário de campo será doravante denominado de DC. 
essas questões como construídas e sim "naturalizadas". Se forem construídas podem ser modificadas, uma vez "naturalizadas" não é possível modificar, há que se conformar com a natureza.

Outro fenômeno a se observar é que os/as estudantes se percebem de forma diferenciada no que diz respeito ao comportamento. Nos trechos citados a seguir pode-se perceber tal diferença na percepção dos/as estudantes. A "bagunça" é vista como um comportamento mais predominante nos meninos. Porém nas observações pude perceber que elas encontravam formas de se divertir durante as aulas, de forma mais discreta e silenciosa do que eles, porém tão frequente quanto. Ou seja, as "bagunças" eram diferentes, porém existiam tanto entre os meninos quanto entre as meninas. $A$ maioria dos/as entrevistados reconhecia na desordem um fator que atrapaIhava o rendimento escolar, como relata Gervásia no excerto a seguir. Fernanda ressalta que o fato delas falarem mais alto dava a sensação de que elas eram mais bagunceiras. Convém ressaltar que nesta classe os "papéis" se invertiam. Os meninos eram mais discretos e silenciosos e as meninas mais participativas, barulhentas, desordeiras e obtinham as melhores notas diferentemente das outras turmas nas quais as meninas eram menos participativas e mais discretas.

A: Quem é mais bagunceiro os piás ou as meninas?

B: Oh... os piás fazem bastante bagunça mas é que a gente fala mais alto então dá a impressão de que a gente faz mais bagunça mas é que por exemplo os meninos tão lá no grupinho deles e tem só duas meninas ali as meninas falam mais alto que eles entendeu? só que eles fazem mais bagunça entendeu as vezes eles ficam gritando assim soltam uma gargalhada sei lá. (Fernanda, $7^{\mathrm{a}}$ série)

A:O que interfere no teu rendimento?

B: Bagunça... interfere bastante.

A: Bagunça dos colegas ou quando você conversa?

B: Eu não converso tanto pra ser bem sincera... quando a professora tá explicando quando eles fazem pergunta ... ai é isso é aquilo... as vezes elas me chamam eu falo ah deixa eu prestar atenção que ela tá explicando coisa assim... mas eu acho que a bagunça mesmo dos meninos ... interfere bastante.

A: Quem é mais bagunceiro?

B: Os meninos... com certeza os meninos. (Gervásia, $6^{a}$ série) As meninas estão mais concentradas do que os meninos. Eles pedem mais auxílio da professora. [Isso pode significar que elas sabem mais a matéria, mas pode significar também que têm mais receio de recorrer à professora para esclarecer dúvidas. Pode significar menos interesse delas em tirar boas notas. Ou significar ainda que eles estão utilizando de todas as armas 
De modo geral, os/as estudantes percebiam os meninos como mais desordeiros, porém não negavam que as meninas também faziam parte da desordem, mas de forma diferenciada. Esta diferença de postura de alunos e alunas era percebida pelos/as professores/as e entendida como normal do comportamento masculino e feminino. Ao enxergar como normal, ações que poderiam minimizar esta questão não eram tomadas e atos que poderiam se converter em discriminação e preconceito continuavam a ocorrer no ambiente escolar. A visão de professores/as e estudantes era baseada nos estereótipos de homens e mulheres.

O fato das meninas pedirem menos auxílio às/aos professoras/es pode indicar que elas foram silenciadas. Desde muito cedo aprendem que devem ouvir mais do que falar. Ficou evidente que as professoras da $5^{\mathrm{a}}$ e $6^{\mathrm{a}}$ séries davam mais atenção aos meninos, fato que estimulava a maior participação deles e o silenciamento delas. Este silenciamento gerava dificuldade de expor suas fraquezas e dúvidas e dificultava o aprendizado delas.

Percebeu-se que os/as estudantes utilizavam-se de estratégias diferentes para atingir suas ambições que eram muito próximas. Embora diferentes todas as estratégicas se mostravam eficientes e os/as ajudavam. As estratégias eram vinculadas às características percebidas como naturais de cada gênero. Ou seja, os/as estudantes se adaptavam às possibilidades de cada um/a. Da mesma forma que a postura dos/as jovens dependia dos estereótipos, as estratégias encontradas pelos/as estudantes eram baseadas em tais estereótipos. Romper as regras é uma forma de fazer valer suas vontades e demonstrar que não existe uma submissão completa ao que é determinado pelo/a professor/a. É uma forma de se apropriar do poder e fazê-lo circular, no conceito de Foucault (2009).

Da mesma forma que os/as estudantes, os/as professores/as percebiam as meninas e meninos com comportamentos diferenciados. Elas eram vistas como mais caprichosas, dedicadas e esforçadas e ele como mais desleixados, ativos e participativos. Embora houvesse este comportamento diferenciado, não era possível perceber reflexo do mesmo nos rendimentos dos/as estudantes.

As relações de gênero eram silenciadas, não percebidas por profes- 
sores/as e estudantes. Louro (2001) argumenta que tão importante quanto escutar o que é dito é perceber o que é silenciado. Por que há este silenciamento? Esta é uma pergunta importante a ser feita quando se depara com uma situação destas. Nesta pesquisa pode-se perceber que os/as profissionais não percebiam as relações de gênero como fator que influenciava no processo ensino/aprendizagem. Porém o silenciamento das meninas era um componente que influenciava no desempenho delas. Elas se calavam diante das dúvidas. Tentar entender os motivos que levam ao silenciamento é fundamental para as discussões de gênero e para a melhora do processo de ensino/aprendizagem.

A vergonha foi apontada como causa para que os estudantes silenciassem no que diz respeito às dúvidas durante as aulas. Os/as estudantes tinham vergonha de perguntar, com receio da reação dos/as colegas. Assim, o acúmulo das dúvidas se reflete em baixo desempenho escolar. Aponta ainda a necessidade de pertencimento ao grupo por parte dos/as estudantes. Eles/as precisam ser conhecidos/as e reconhecidos/as pelos/ as colegas como um/a deles/as e por isso silenciam com receio de que, ao expor suas ideias, possam ser vistos como diferentes como não pertencentes àquele grupo. Se a ideia fosse correta seriam chamados de "CDF"12 e se fosse equivocada seriam rotulados de "burros". Ambas as situações não eram desejadas pelos/as estudantes, então, calavam-se. Os/as professores/as não percebiam este silenciamento e não tomavam providências para melhorar a participação dos/as estudantes.

Percebeu-se uma recusa em assumir a participação dos/as entrevistados/as nas ações vexatórias. Esse fato fica perceptível na fala de Braulin, aluno da $5^{\mathrm{a}}$ série. Ele começa a dizer que ele faz, mas, em seguida se corrige e diz que todos os meninos tiram sarro dos colegas. Por outro lado, a fala de Bianca evidencia o silenciamento que pode indicar o receio de ser vítima de chacotas. Sem dúvida a vergonha e o receio de serem vitimadas

12 Na gíria dos estudantes CDF significa pejorativamente cabeça de ferro, alunos que estudam bastante e tiram boas notas. 
fazem com que as relações em sala de aula se modifiquem e tornem-se menos ricas.

A: Em algum momento você percebeu que alguém fez um pergunta e o outro tirou sarro ....acontece isso?

$\mathrm{B}$ : Acontece...também ontem... o Ivo as veis ele fais pergunta... ele :.: a professora... todo mundo já tá sabendo... coisa facinha... coisa nada a vê assim ele pega e pergunta... mas professora esse daqui é diferente desse número que igual a esse daqui... bem nada a vê as perguntas daí eu tira... daí os piá tira sarro daí. (Braulin, $5^{\mathrm{a}}$ série)

A: E como você acha que as pessoas que perguntaram se sentem quando alguém tira sarro delas?

$B$ : Elas se sentem magoadas.

A: Já tiraram sarro de alguma pergunta que você fez?

B: Eu não faço pergunta então não tem... eu não faço pergunta. (Bianca, $5^{\mathrm{a}}$ série)

Durante a pesquisa pude perceber que os/as estudantes mais participativos/as eram também os que obtinham as melhores notas. Porém não foi possível concluir se eles perguntavam mais por terem mais conhecimento o que os deixaria seguros para se expor ou se tinham melhores rendimentos por que perguntavam mais e elucidavam suas dúvidas, talvez seja as duas coisas.

O comportamento dos/as colegas com relação às dúvidas dos demais interferia na postura dos estudantes durante as aulas de Matemática e poderia contribuir para o baixo rendimento dos mesmos, fato observado nas análises dos diários de classe (CASAGRANDE; CARVALHO, 2011). Esta postura dos/as colegas interfere mais no comportamento das meninas do que dos meninos.

No que diz respeito às notas obtidas pelos/as estudantes, em sua maioria eram baixas, ficando as médias das turmas muito próximas ao mínimo necessário para a aprovação que no estado do Paraná é 6 (seis), porém todas as médias eram baixas.

A iniciativa dos meninos de perguntar mais e o comportamento disciplinado das meninas não resultava em boas notas (CASAGRANDE; CARVALHO, 2011). Embora existisse diferença entre o rendimento dos alunos e das alunas, não foi possível concluir que esta diferença levava à superação de um sexo sobre outro, pois em duas turmas a vantagem favorecia às alunas e nas outras duas, aos alunos. Porém, na percepção dos/as estudantes 
o melhor rendimento era das alunas. Talvez pelo fato de que elas eram percebidas como mais dedicadas, organizadas e estudiosas, os/as estudantes acreditavam que o rendimento delas era melhor e que resultaria em melhores notas, fato que não necessariamente acontecia.

Ao serem questionados/as sobre as expectativas profissionais a maioria dos/as jovens afirmou que pretendia cursar nível superior. Seis estudantes (15\%) gostariam de cursar as engenharias (quatro alunos e duas alunas) e sete $(17,5 \%)$ seguir carreiras relacionadas à área da saúde (três alunos e quatro alunas). Este fato indica que os/as jovens da escola pública almejavam seguir carreiras valorizadas financeira e socialmente. Este é um indício de que a escola pública está oferecendo condições para que os/as jovens almejem estudos superiores nas mais variadas áreas. Estimular os/ as estudantes a prosseguir sua vida escolar é um dos papéis da escola, que, aparentemente está sendo cumprindo.

Não foi possível estabelecer uma relação direta entre o rendimento em Matemática e as expectativas profissionais, porém os/as estudantes que almejavam as engenharias e as carreiras da área médica obtiveram bom rendimento em Matemática no ano pesquisado (2009). Por meio deste indicativo podemos dizer que o bom desempenho em Matemática contribui para a expectativa profissional. Mesmo que o rendimento escolar em Matemática não seja um indicativo claro, pode-se dizer que é um dos fatores que influenciam nas expectativas profissionais.

Ainda sobre a relação dos/as estudantes com a Matemática, a maioria afirmou gostar da disciplina, porém seus rendimentos eram vistos por ele/as como médios. Outros diziam que o rendimento era baixo, mas mesmo assim gostavam da Matemática. Este resultado contraria a ideia corrente de que os/as estudantes não gostam de Matemática.

\section{Considerações finais}

De modo geral, as questões de gênero se mostraram imperceptíveis para estudantes e professores/as como fator que influenciava no rendimento escolar de alunos e alunas. Este silenciamento sobre as relações de gênero indicava a naturalização destas questões no ambiente escolar. Tão 
naturais que se tornavam quase imperceptíveis e silenciadas por todos/as os/as participantes da pesquisa. Não perceber como as relações de gênero influenciam na relação de meninos e meninas com a Matemática é desperdiçar oportunidades de enriquecimento do processo ensino/aprendizagem. É deixar de proporcionar melhores condições de aprendizagem a todos/as.

Os/as estudantes e professores/as manifestaram ter absorvido as normas impostas pela socialização diferenciada de meninos e meninas, nas quais elas são ensinadas a cuidar, a preservar seus brinquedos e objetos pessoais, viver no espaço doméstico e por consequência, a serem delicadas, cuidadosas e caprichosas enquanto eles são incentivados a experimentar, desmontar e montar novamente seus carrinhos e brinquedos, viver no espaço público, podendo então, se arriscar, não tendo a obrigação com o cuidado e capricho. A socialização ensina mulheres a silenciar a não se expor e não expor suas ideias e isso se reflete na escola onde as meninas silenciam diante das diversas situações. Esta socialização diferenciada que ocorre de várias formas contribui para que homens e mulheres construam e manifestem de forma diferente suas expectativas de vida e profissionais. Sem dúvidas a escola contribui para a construção diferenciada de identidades masculina e feminina.

As relações de gênero são repletas de poder que perpassam as relações do cotidiano e se manifestam em sala de aula. Porém docentes e discentes não as percebem, não se dão conta de que elas estão interferindo no seu dia a dia, no seu aprendizado, no seu relacionamento interpessoal. Mesmo de forma diferenciada, os/as estudantes encontravam maneiras eficientes de manifestar seu poder, de fazê-lo transitar, circular no espaço da sala de aula. Ou seja, mesmo sendo educadas a calar, a silenciar e a obedecer, as meninas encontravam formas de fazer uso do poder circulante e atingir seus objetivos.

O fato das relações de gênero presentes no cotidiano escolar raramente serem percebidas pelos sujeitos que nele atuam faz com que sejam negligenciadas e silenciadas por todos/as. Tanto as relações de gênero quanto as meninas são silenciadas e se silenciam diante das situações do cotidiano escolar. As meninas são silenciadas ao não serem percebidas nem ouvidas pelos professores/as e ao serem descritas como mais obedientes pelos 
discentes, se silenciam ao aceitarem esta situação e ao deixar de tentar se mostrar, se impor.

Embora não se concorde com a concepção de gênero como papéis dicotomizados, o que se observou na pesquisa é que meninos e meninas se percebiam como pertencentes a mundos diferentes, com interesses e desejos distintos. Ou seja, se percebiam exercendo papéis sociais, como se existisse coisas e atitudes apropriadas para uns e para outras.

Os/as professores/as se mostraram despreparados/as para lidar com as situações de preconceito e discriminação fato que demonstra a necessidade de se preparar os/as professores/as para tratar as questões de gênero que ora são quase imperceptíveis aos seus olhos.

Os resultados da pesquisa apontam para o fato de que as relações de gênero se fazem presentes no cotidiano escolar, entretanto não são percebidas ficando, desta forma, ocultas, silenciadas, invisíveis, negligenciadas.

\section{Referências}

CASAGRANDE, Lindamir Salete; CARVALHO M. G., Marilia Gomes (2011). Desempenho escolar em Matemática: o que o gênero tem a ver com isso? In: CASAGRANDE, Lindamir Salete; LUZ, Nanci Stanckida., CARVALHO, Marilia Gomes de. (Orgs) Igualdade na Diversidade: enfrentando o sexismo e a homofobia. Curitiba: Editora da UTFPR, p. 269-306.

CASAGRANDE, Lindamir. Salete. Entre silenciamentos e invisibilidades: relações de gênero no cotidiano das aulas de matemática. 2011, 261f. Tese (Doutorado em Tecnologia), Programa dePós-Graduação em Tecnologia, Universidade Tecnológica Federal do Paraná, Curitiba, 2011.

COSTA, Claudia de Lima. (1994) O leito do procusto. Cadernos Pagu, Campinas, p. 141-174.

FELIPE, Jane; GUIZZO, Bianca Salazar. (2003). Erotização dos corpos infantis na sociedade de consumo. Pro-Posições, Campinas, v. 14, n. 3 (42), p. 121-130.

FOUCAULT, Michel (2009). Microfísica do poder. 27. reimp. Rio de Janeiro: Edições Graal. 
LOURO, Guacira Lopes (2001). Gênero, sexualidade e educação: uma perspectiva pós-estruturalista. Petrópolis: Vozes.

RAGO, Margareth (1998). Descobrindo historicamente o gênero. Cadernos Pagu, Campinas, 11,p. 89-98.

SARMENTO, Manuel J (2003). O estudo de caso etnográfico em Educação. In: ZAGO, N; CARVALHO, M. P.; VILELA, R. A. T. (Orgs.). Itinerários de Pesquisa. Rio de Janeiro: DP\&A, p. 109-136.

SCOTT, Joan. (1995) Gênero: Uma categoria útil de análise histórica. Educação \& Realidade, Porto Alegre, v. 20, n. 2, p. 71-99.

SIMIÃO, Daniel Schroeter (2005). Gênero no mundo do trabalho: variações sobre um tema. Cadernos de Gênero e Tecnologia, v. 5, ano 2, p. 9-20. 